\title{
Penatalaksanaan Sinus Preaurikuler Tipe Varian Dengan Pit pada Heliks Desenden Postero-Inferior
}

\author{
Jacky Munilson, Effy Huryati, M. Rusli Pulungan
}

\section{Abstrak}

Sinus preaurikuler merupakan kelainan kongenital berupa adanya lubang kecil pada telinga luar yang biasanya terdapat di anterior dari heliks asendens. Disamping lokasi tersebut, sinus preaurikuler juga dapat ditemukan posterior dari liang telinga luar yang dikenal sebagai sinus preaurikuler tipe varian. Sinus preaurikuler tipe varian merupakan kasus yang jarang dilaporkan. Kebanyakan kasus tidak menunjukkan gejala, sebagian lainnya mengalami masalah infeksi berupa keluarnya cairan, atau terbentuknya abses. Penatalaksanaan sinus preaurikuler adalah dengan pengangkatan sinus secara lengkap. Kekambuhan merupakan masalah yang dapat timbul jika tidak diangkat secara lengkap.

Dilaporkan satu kasus sinus preaurikuler tipe varian dengan pitberada pada heliksdesendens postero-inferior dekat lobulus pada seorang anak laki-laki umur 3 tahun 6 bulan dan ditatalaksana dengan sinektomi.

Kata kunci: Sinus preaurikuler, sinus preaurikuler tipe varian, sinektomi.

\begin{abstract}
Preauricular sinusis a congenital malformation that manifests as pit in the extenal ear, usually located in the anterior limb of ascending helix. In additional to these location, preauricular sinus can also be found in the posterior of the external ear canal, known as the preauricular sinus with variant type. Preauricular sinus variant type is a rarely reported. Almost cases are asymptomatic, but others are infectious with discharge or abscess formation. The management of preauricular sinus is excision sinus completely. Recurrence is the problem that happen if the excision was not complete. One case of preauricular sinus variant type with pit on the postero-inferior decending helixnear lobulus in a boy 3 years and 6 months old and managed bysinectomy.
\end{abstract}

Keywords: Preauricular sinus, Preauricular sinus variant type, sinectom

Affiliasi penulis : Bagian THT-KL fakultas Kedokteran Universitas Andala

Korespondensi :Jacky Munilson, Bagian THT-KL Fakultas

Kedokteran Universitas Andalas Padang.

\section{Pendahuluan}

Sinus preaurikuler atau sering juga disebut fistula preaurikuler pertama kali dikenalkan Heusinger pada tahun 1864. Merupakan kelainan kongenital yang sering pada anak. Kelainan ini terlihat berupa lobang kecil (pit) didekat anterior heliks asendens. Biasanya berada anterior dari liang telinga luar. ${ }^{1-6}$

Sinus preaurikuler sering tidak memperlihatkan gejala klinis. Pasien biasanya tidak peduli dengan kelainan ini. sering ditemukan pada saat pemeriksaan fisik atau setelah adanya infeksi. Kekerapan diperkirakan mencapai 0,1\%-0,9\% di Amerika Serikat, 2\%-4\% di Asia, 4\%-10\% di berbagai wilayah Afrika. $^{1-3,7}$

Sinus preaurikuler terbentuk selama masa embriogenesis. Daun telinga dibentuk pada usia kehamilan 6 minggu berasal dari arkus brankial pertama dan kedua. Jaringan dari kedua arkus brankial ini berkembang membentuk 6 hiloks, yang akan bergabung membentuk telinga luar. Tiga hiloks berasal dari batas kaudal arkus brankial pertama dan 3 hiloks lainnya berasal dari batas sefalik dari arkus brankial ke dua yang akan bergabung setelah beberapa minggu embriogenesis. Kegagalan penyatuan 6 hiloks atau adanya epitel ektoderm yang terperangkap selama pembentukan daun telinga mengakibatkan terjadinya sinus preaurikuler. ${ }^{1-4,8-10}$ (Gambar 1. )

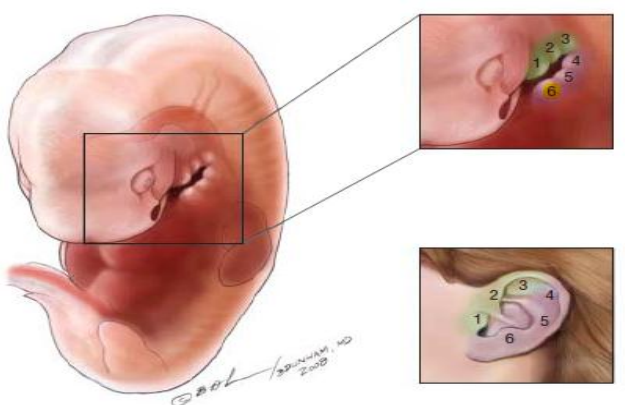

Gambar 1. Fetus usia 42 harikehamilanterlihat 6 hiloks ${ }^{7}$

Sinus preaurikuler sering tanpa gejala, hanya terlihat adanya suatu lobang kecil di daerah sekitar heliks asendens. Namun jika mengalami infeksi akan muncul gejala berupa pembengkakan, terasa nyeri dan mengeluarkan cairan yang berbau. Infeksi ini sering mengalami kekambuhan dan kadang dapat terjadi abses. Pada beberapa pasien dapat terjadi infeksi yang kronis dengan sekret yang keluar hilang timbul. ${ }^{1,1}$

Disamping sinus preaurikuler dengan pit yang berada di dekat anterior heliksasendens, juga dapat ditemukan sinus preaurikuler dengan lokasipit berada disekitar posteriorheliksasendens dengan sakus pada daerah postaurikuler. Sinus preaurikuler seperti ini dikenal sebagai tipevariandari sinus preaurikuler. Namun pada kenyataannya walaupun sangat sedikit didapatkan, ada laporan yang meperlihatkan adanya sinus dengan pit berada pada sepanjang superoposterior dari heliks, tragus maupun lobulus. ${ }_{1,2,10,12}$ 
Choi $\mathrm{dkk}^{1}$ menemukan beberapa tipe varian dari sinus preaurikuler dan membaginya kedalam tipeklasik dan tipe varian, yaitu:

a. Tipe klasikyaitu sinus preaurikuler mempunyai pit di anterior dari garis imajiner yang menghubungkan tragus dengan sisi posterior heliks asenden.

b. Tipe varian sinus preaurikuler adalah sinus preaurikuler dimana pitberada di bagian posterior dari garis imajiner yang menghubungkantragus dengan sisi posterior heliks asenden:

- Tipe 1: lokasi pit pada daerah tengah dari krus.

- $\quad$ Tipe 2: lokasi pit pada daerah superior dari krus.

- $\quad$ Tipe 3: lokasi pit pada simba konka.(Gambar 2.)

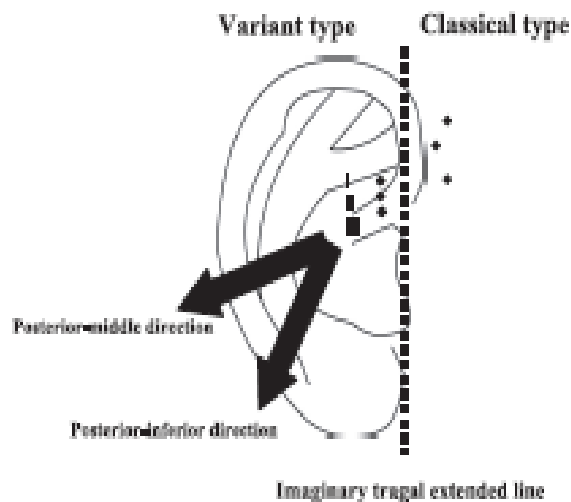

\section{Gambar 2. Sinus preaurikulertipevarian ${ }^{1}$}

Sinus preaurikuler dengan pit yang berada pada helikspostero-inferior merupakan tipe varian yang sangat jarang. Sampai saat ini belum ada ditemukan laporan sinus preaurikuler seperti ini.

Kuman penyebab infeksi sinus preaurikuler didapatkan; Staphylococcus epidermidis, Staphylococcus aureus, Streptococcus viridans, Peptococcus sp, dan Proteus sp.

Pengobatan sinus preaurikuler diindikasikan jika ada gejala. Pengangkatan sinus secara lengkap merupakan pengobatan definitif dan akan mencegah terjadinya kekambuhan., ${ }^{1,6}$ Pengangkatan sinus dilakukan bila infeksi telah dapat diatasi. ${ }^{6}$

Teknik operasi terdiri dari infiltrasi vasokonstriktor, insisi elips pada sekeliling pit dan kemudian dilakukan diseksi dari saluran sinus. Metilen blue dipakai sebagai pewarna untuk menandai saluran dari sinus. ${ }^{5}$

Sinus preaurikuler mempunyai prognosis yang baik jika sinus dapat diangkat secara lengkap. Pembentukan sikatrik tergantung keahlian ahli bedahnya dan faktor pasien itu sendiri. ${ }^{8}$

\section{Laporan Kasus}

Seorang anak laki-laki umur 3 tahun 6 bulan datang ke Poliklinik THT-KL RSUP Dr. M. Djamil Padang pada tanggal 11 April 2011 dengan keluhan utama bengkak di bagian belakang daun telinga kanan yang mengeluarkan cairan yangberbau. Bengkak sudah ada sejak kecil. Keluar cairan berwarna putih kekuningan yang berbau hilang timbulsejakumur 1 tahun. Bengkak kadang terasa sakit bila sedang infeksi.Terdapat lubang kecil dipuncak pembengkakan. Lobang kecil ini telah terlihat sejak anak lahir. Riwayat trauma pada telinga tidak ada. Gangguan pendengaran tidak ada, dapatberbicara dengan lancar sesuai dengan usianya, dan telah mulai bicara sejak umur 1 tahun. Anak pertama dan belum mempunyai adik. Tidak ada anggota keluarga yang sakit seperti ini. Buang air kecil biasa. Demam tidak ada. Pasien telah berobat 2 minggu sebelumnya dengan keluhan yang sama dan telah diberi terapi antibiotik. Saat ini cairan yang keluar sudah minimal.

Pada pemeriksaan fisik ditemukan keadaan umum baik, kesadaran komposmentis kooperatif dan tidak demam. Pada pemeriksaan lokalis THT didapatkan telinga kiri dalam batas normal. Telinga kanan; pada daun telinga kananterdapat bengkak pada daerah helikssedikit diatas lobulus, membesar kearah belakang permukaan sama dengan kulit sekitarnya.Konsistensi kenyal padat, tidak nyeri, berbatas tegas, ukuran $1,5 \mathrm{~cm} \times 1,5 \mathrm{~cm} \times 1 \mathrm{~cm}$ terdapat lubang kecil di puncak pembengkakan, terdapat cairan berwarna putih keruh berbau. Retroaurikuler dekstra tidak ada kelainan. (Gambar 3) Liang telinga lapang, membran timpani utuh refleks cahaya positif. Hidung dan tenggorok dalam batas normal.

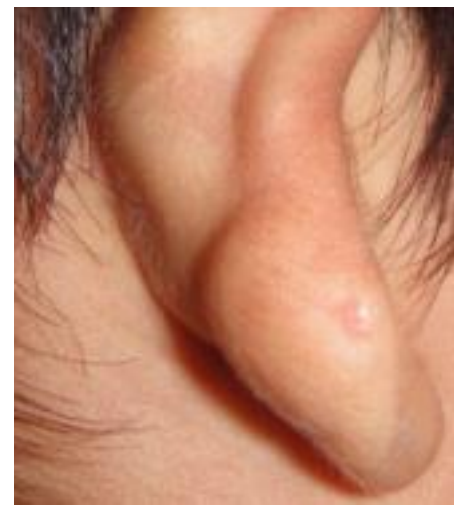

\section{Gambar 3. Sinus pada aurikel dekstra pra operasi}

Diagnosis kerja pada saat ini ditegakkan suspek sinus preaurikuler tipe varian auris dekstra dengan diagnosis banding kista terinfeksi. Terapi yang diberikan amoksilin asam klavulanat syrup 3x125mg. Direncanakan untuk sinektomi dalam narkose umum.

Pada pemeriksaan laboratorium darah didapatkan hemoglobin $12,1 \mathrm{~g} \%$, leukosit $12.000 / \mathrm{mm}^{3}$, hematokrit $38 \%$, trombosit $180.000 / \mathrm{mm}^{3}$, PT 12,0, APTT 41,4

Pada tanggal 19 April dilakukan operasi sinektomi dalam narkose umum. Laporan operasi:

* Pasien tidur terlentang di meja operasi dalam narkose umum.

* Dilakukan proseduraseptik anstiseptik di daerah operasi.

* Dilakukan evaluasi saluran sinus dengan jarum iv kateter no 18 masuk lebih kurang $1,5 \mathrm{~cm}$ ke arah medial posterior konka.

* Dilakukan infiltrasi dengan lidokain : epinefrin 1:200.000.kemudian saluran sinus ditandaidengan menyuntikkan metilen blue ke dalam sinus.

* Insisi elips pada daerah sekitar pit.

* Saluran dicari dan dilepas dari jaringan sekitar secara tajam.

* Sakus ditemukan melengket ke kartilago konka.

* Sakus diangkat bersama dengan kartilago konka tempat sakus menempel, dan dikirim ke bagian Patologi Anatomi untuk dilakukan pemeriksaan histopatologi. (Gambar 4.) 
* Luka operasi dibersihkan dan dijahit tanpa dipasang salir. (Gambar 5.)

* Operasi selesai.

\section{Gambar 4. Sinus yang telah diangkat}

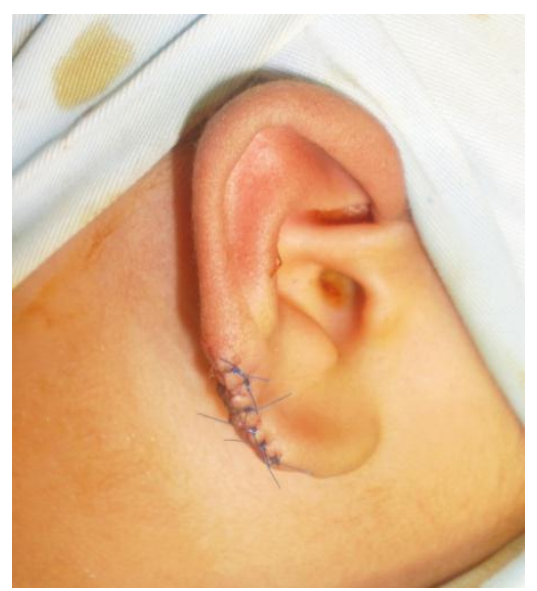

\section{Gambar 5. Pasca operasi sinektomi}

Diagnosis pasca operasi adalah
pascasinektomiatas indikasi sinus preaurkuler tipe
varian auris dektra.Pasiendiberiterapiinjeksi
seftriakson $2 \times 300 \mathrm{mg}$ iv, ibuprofen syrup $2 \times 100 \mathrm{mg}$.
Pada kontrol hari kedua pasca operasi
terlihat luka operasi kering, tidak ada tanda infeksi, demam tidak ada. Pasien boleh pulang dan diberikan terapi amoksilin asam klavulanat syrup $3 \times 125 \mathrm{mg}$ dan ibuprofen syrup $2 \times 100 \mathrm{mg}$. Anjuran kontrol 4 hari lagi ke poliklinik THT-KL RSUP Dr. M. Djamil Padang.

Kontrol tanggal 25 April 2011 didapatkan keadaan umum pasien baik, kesadaran komposmentis kooperatif, demam tidak ada. Luka operasi kering tanda infeksi tidak ada. Jahitan dibuka. (gambar 6.) Terapi amoksilin asam klavulanat 3x125mg.

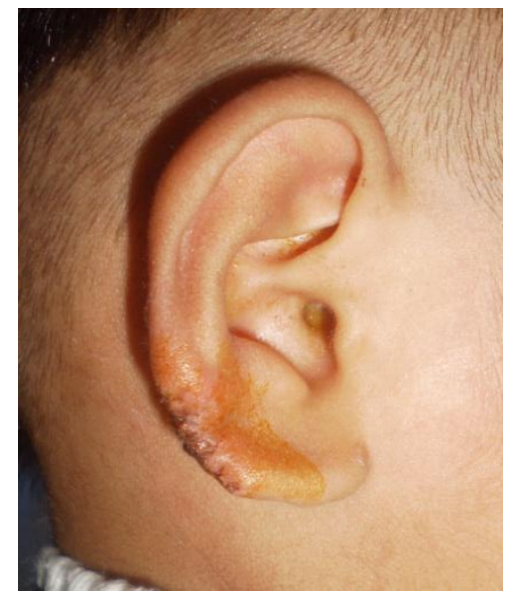

\section{Gambar 6. Pasca sinektomi hari ke-6}

Pada tanggal 2 Mei 2011 kondisi pasien baik keluhan tidak ada luka operasi sudah sembuh. Hasil pemeriksaan histopatologi No. PA: PJ-499-11 tanggal 27 April 2011 didapatkan potongan jaringan pada permukaan dilapisi oleh epitel berlapis gepeng, dibawahnya terdapat jaringan ikat yang mengandung folikel rambut, jaringan lemak, sebukan ringan sel-sel limfosit, serta adanya rongga yang dilapisi oleh epitel berlapis gepeng. Gambaran ini sesuai untuk suatu sinus. (Gambar 7.)

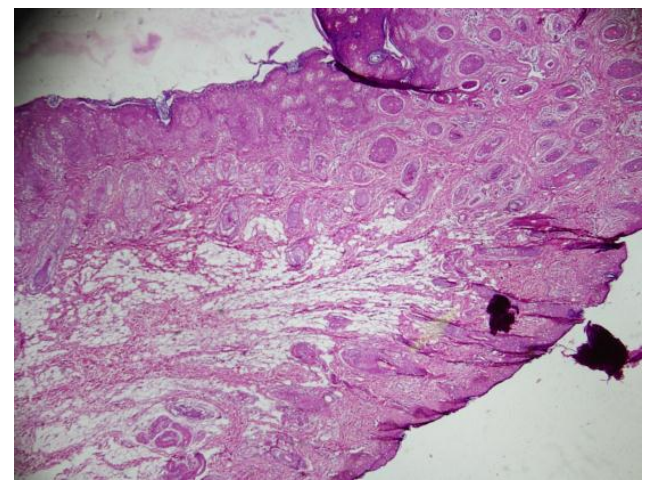

Gambar 7. Histopatologi sinus terlihat saluran dengan dinding yang dilapisi sel epitel gepeng berlapis

Diskusi

Telah dilaporkan satu kasus sinus preaurikuler tipe varian pada seorang anak laki-laki umur 3 tahun 6 bulan yang telah dilakukan sinektomi. Sinus preaurikuler merupakan kasus yang sering didapatkan pada anak. Namun hanya sedikit yang menimbulkan gejala sehingga tidak banyak perhatian penderita terhadap kelainan ini. Biasanya kelainan diketahui pada saat pemeriksaan fisik atau setelah adanya komplikasi sehingga penderita datang berobat. $^{6}$

Prevalensi sinus preaurikuler tidak diketahui dengan pasti. Namun pada beberapa kepustakaan disebutkan prevalensi sinus preaurikuler berkisar 0,1\%-0,9\% di Amerika serikat. Di Taiwan diperkirakan $1,6 \%-2,5 \%$, Inggris 0,9\%, Skotlandia 0,06\%, Hungaria $0,47 \%$ dan pada beberapa kawasan Afrika mencapai 4-10\%. ${ }^{2,3,7}$ Di RSUP Dr. M. Djamil Padang selama tahun 2010 telah dilakukan operasi sinektomi sinus preaurikuler sebanyak 4 orang, semuanya merupakan tipeklasik. Ras kulit putih lebih rendah dibanding kulit 
berwarna seperti Asia dan Afrika. Perempuan lebih banyak dibanding laki-laki. Biasanya unilateral dan lebih banyak sebelah kanan. ${ }^{7}$ Pada pasien ini didapatkan unilateral pada sebelah kanan.

Sinus preaurikuler merupakan kelainan kongenital yang terjadi akibat tidak sempurnanya penyatuan 6 hiloks atau akibat epitelektoderm yang terperangkap selama masa pembentukan telinga luar pada usia kehamilan 6 minggu. Perkemangan ke-6 hilloks ini akan membentuk bagian-bagian telinga luar. Hilloks I membentuk tragus, hilloks II membentuk crus heliks, hilloks III membentuk heliks, hilloks IV membentuk anti heliks, hilloks $\mathrm{V}$ membentuk anti tragus dan hilloks VI membentuk lobulus dan heliks bagian bawah. Lokasi sinus preaurikuler yang klasik berada superoanterior liang telinga luar dan pit terletak di anterior heliks asendens. ${ }^{1-4,7,8,9}$ Pada kasus ini kemungkinan terjadi kegagalan pada perkembangan hilloks VI.

Pada pasien ini ditemukan adanya sinus preaurikulerdenganlokasi pitpada daerahheliks desendens postero-inferior dekat dengan lobulus. Kelainan ini merupakan keadaan yang jarang ditemukan, dan sampai saat ini belum ada ditemukan laporan sinus preaurikuler seperti ini.

Secara umum sinus preaurikuler klasik dikenal sebagai sinus yang pitnya terdapat di daerah sekitar heliks asendens di depan liang telinga luar, demikian juga tipe varian yang digambarkan oleh Choi $\mathrm{dkk}^{1}$ bahwa sinus preaurikuler tipe varian merupakansinus denganpitberada di posterior dari garis imajiner yang menghubungkan tragus dengan sisi posterior heliks asenden. Sakus biasanya terdapat di daerah posterior daun telinga dan sering menembus kartilago. Namun juga disebutkan bahwa pit sinus preaurikuler tipe varian dapat ditemukan pada sepanjangsupero-posterior dari heliks, tragus dan lobulus. Namun dilaporkan kasusnya sangat jarang. ${ }^{1,2,12}$

Berdasarkan lokasi pembengkakan yang tidak lazim dari sinus preaurikuler ini membuat kita harus mendiagnosis banding dengan suatu kista yang terinfeksi. Lokasi pit terbanyak adalah di anterior helik asendens $93,2 \%$, terbanyak kedua adalah di sekitar permukaan posterior krus heliks atau simba konka. Lokasi lain adalah bagian superior heliks asendens, postaurikuler, dan lobulus. ${ }^{13}$

Kejadian sinus preaurikuler tipe varian jarang dilaporkan. Chang $\mathrm{dkk}^{2}$ melaporkan hanya 3 kasus sinus preaurikuler dengan sakus pada posterior telinga yang terinfeksi. Yeo $\mathrm{dkk}^{13}$ melaporkan 8 kasus sinus preaurikuler tipe varian dari 206 kasus sinus preaurikuler, pit terdapat di simba konka dan 2 berada pada postaurikuler. Choi $\mathrm{dkk}^{1}$ melaporkan sinus preaurikuler tipe varian $11(10,9 \%)$ dari 101 pasien yang didiagnosis sinus preaurikuler.

Sinus preaurikuler merupakankelainan kongenital yang dapat muncul bersamaan dengan kelainan kongenital yang lain dan membentuk suatu sindroma.Huang $\mathrm{dkk}^{11}$ dari 121 penderita sinus preaurikuler didapatkan 2 orang $(1,7 \%)$ menderita kelainan tulisensorineural yang ringan dan sedang, tanpa ada kelainan fisik yang lain,dansebanyak 3 orang $(2,6 \%)$ ditemukan kelainan struktur ginjal. Wang $\mathrm{dkk}^{14}$ melaporkan dari 69 anak dengan sinus preaurikuler ditemukan kelainan ginjal $3(4,3 \%)$ anak, 2 anakdengan kelaian ginjal saja, 1 anak dengan brankio-oto-renal. Brankio-oto renal sindrom merupakan kelainan autosomal dominan dengan karakteristik berupa penurunan pendengaran, sinus preaurikuler, celah brankial, gagal ginjal kronik yang progresif dengan onset yang cepat. ${ }^{15,16}$ Untuk melihat adanya kelainan kongenital lain pada pasien ini perlu dilakukan pemeriksaan anjuran seperti pemeriksaan pendengaran maupun pemeriksaan ginjal. Pemeriksaan dilakukan jika ada indikasi, seperti adanya riwayat keluarga dengan kelainan pendengaran, gangguan pendengaran dan lainnya. ${ }^{17}$

Pada temuan operasi didapatkan sinus ini dengan saluran yang pendek berkisar $1,5 \mathrm{~cm}$ dengan arah ke medio anterior dan melekat ke kartilago dari konka. Hal ini juga berbeda dengan yang dilaporkan para ahli bahwa sinus preurikuler tipe varian mempunyai saluran yang lebih panjang dengan arah postero-medial atau postero-inferior dari pit. ${ }^{1}$ Choi dkk ${ }^{1}$ menemukan arah saluran dari sinus preaurikuler tipe varian postero-medial $72,8 \%$, dan arah posteroinferior $27,2 \%$. Saluran sinus tipe varian juga sering menembus kartilago sampai ke posterior daun telinga.

Pasien ini telah dilakukan sinektomi atas indikasi pembengkakan dan infeksi yang berulang. Eksisi sinus preaurikuler diindikasikan jika sering mengeluarkan sekret atau infeksi berulang dan jika terdapat abses. Penandaan saluran sinus memakai metilen blue. Tang $\mathrm{dkk}^{18}$ memakai 2 modalitas untuk menandai saluran sinus selama operasi yaitu dengan menggunakan metilen blue dan probe. Penulis lain menganjurkan pemakaian mikroskop untuk pengangkatan sinus yang lengkap. Penandaan saluran sinus dan pemakaian mikroskop dimaksudkan untuk dapat mengangkat sinus secara lengkap., ${ }^{2,19}$

Angka kekambuhan meningkat jika pengangkatan sinus preaurikuler tidak lengkap. Teknik operasi memegang peranan penting dalam pengangkatan sinus yang lengkap. Angka kekambuhan sinus preaurikuler pasca sinektomi berkisar $19 \%-42 \%$. Tang $\mathrm{dkk}^{18}$ melaporkan 10 dari 51 pasien dengan sinus preaurikuler yang dilakukan sinektomi mengalami kekambuhan.Sinektomi dengan penandaan saluran sinus dengan metilen blue terjadi kekambuhan pada9 (30\%) dari 30 pasien. Pada sinektomi yang menggunakan metilenblue kemudian dipasang probe lakrimal angka kekambuhan hanya $1(4,7 \%)$ dari 21 pasien. Kumar dkk ${ }^{19}$ melakukan eksisi sinus dengan penandaan saluran sinus dan memakai mikroskop pada 9 pasien, tidak ditemukan adanya kekambuhan setelah difollow upselama 18 bulan. Lam $\mathrm{dkk}^{5}$ melaporkan angka kekambuhan sinus preaurikuler dengan sinektomi $32 \%$.

Untuk mengurangi kekambuhan akibat pengangkatan sinus yang tidak lengkap Prasad pada tahun 1990 memperkenalkan teknik pengangkatan sinus dengan pendekatan supra aurikuler. Angka kekambuhan dengan menggunakan teknik pendekatan supra aurikuler ini dilaporkan kurang dari $5 \%$. Lam dkk melaporkan angka kekambuhan sinus preaurikuler dengan teknik pendekatan supraurikuler $3,7 \%{ }^{5}$

\section{Daftar Pustaka}

1. Choi SJ, Choung YH, Park K, Ba J, Park HY. The Variant type of preauriculer sinus: postauriculer sinus. Laryngoscope 2007;117:1798-802.

2. Chang $\mathrm{PH}, \mathrm{Wu} \mathrm{CM}$. An insidious preauricular sinus presenting as an infected postauricular cyst. Int J Clin Pract 2005;59.3:370-2.

3. Tan $\mathrm{T}$, Constantinides $\mathrm{H}$, Mitchell TE. The Preauricular sinus: A review of its aetiology, 
clinical presentation and management. Int $\mathrm{J}$ Ped Otorhinolaryngol 2005;69:1469-74.

4. Scheinfeld NS. Preauricular sinus. Update 2010, Aug 16 [cited 2011 Apr 29]. Available from: www.emedicine.medscape.com/article/1118768overview

5. Lam HCK, Soo G, Wormald PJ, Hasselt CA. Excision of the preauricular sinus: A comparison of two surgical techniques. Laryngoscope 2001;111:317-9.

6. Shu MT, Lin HC. Extirpation of ruptured preauricular fistula. Laryngoscope 2001;111:9246

7. Leopardi G, Chiarella, Conti S, Cassandro E. Surgical treatment of recurring preauricullar sinus: Supra-auricular approach. Acta Otorhinolaryngol Ital 2008;28:302-5.

8. Ostrower ST. Preauricular cyst, pits, and fissures. Update 2009, Feb 12 [cited 2011 Apr 29]. Available from: www.emedicine.medscape.com/article/845288overview

9. Zou F, Peng Y, Wanf X, Liu W, Bai S, Zhu H dkk. A locus for congenital preauricular fistula maps to chromosome 8q11.1-q13.3. J Hum Genet 2003;48:155-8

10. Dunham B, Guttenberg M, Morrisson W, Tom L. The histologic relationship of preauricular sinuses to auricular cartilage. Arch Otolaryngol Head Neck Surg 2009;135:1262-5.

11. Huang $X Y$, Tay GS, Wansaicheong GKL, Low WK. Preauricular sinus. Arch Otolaryngol Head Neck Surg 2007;133:65-8.

12. Scheinfeld NS, Silverberg NB, Weinberg JM, Nozad V. The preauricular sinus: A review of its Clinical presentation, treatment, and associations. Pediatric Dermatology 2004;21(3):191-6
13. Yeo SW, Jun BC, Park SN, et al. The preauricular sinus: Factor $s$ contributing to recurence after surgery. Am J Otolaryngol Head Neck 2006;27(6):396-400.

14. Wang RY, Earl DL, Ruder RO, Graham JM. Syndroma Ear Anomalis and Renal Ultrasounds. Pediatric 2001;108: 1-8

15. Pierides AM, Athanasiou $\mathrm{Y}$, Demetriou $\mathrm{K}$, Koptides M, Deltas CC. A family with the branchio-oto-renal syndrome: clinical and genetic correlations. Nephrol Dial Transplant 2002;17:1014-1018.

16. Dickson JM, Riding KH, Ludemann JP. Utility and safety of methyline blue demarcation of preauricular sinuses and branchial sinuses and fistulae in children. J Otolaryngol Head Neck Surg 2009;38:302-10.

17. Firat $Y$, Sireci S, Yakinci $C$ et al. Isolated preauricular pits and tags: is it necessary to investigate renal abnormalities and hearing impairment? Eur Arch Otolaryngol 2008;265:1057-1060

18. Tang IP, Shasinder S, Kuljit S, Gopala KG. Outcome of patients presenting with preauriculer sinus in a tertiary centre-A five year experience. Med J Malysia 2007; 62(1):53-5.

19. Kumar KK, Narayamurthy VB, Sumathi V, Vijay R. Preauricular sinus: operating microscope improves outcome. Indian J Otolaryngol Head Neck Surg 2006;58:6-8. 